\title{
Analysis of Valorization Process of Aluminum Breakage Scraps to Obtain Green Hydrogen
}

\author{
Xavier Salueña Berna ${ }^{1}$, Marc Marín-Genescà ${ }^{2, *(1)}$ and José María Dagà-Monmany ${ }^{3}$ \\ 1 Mechanical Engineering Department, ESEIAAT-UPC, Colom 11, 08222 Terrassa, Spain; \\ xavier.saluena@upc.edu \\ 2 Mechanical Engineering Department, ETSEQ-URV, Països Catalans 26, 45002 Tarragona, Spain \\ 3 Chemical Engineering Department, ESEIAAT-UPC, Colom 11, 08222 Terrassa, Spain; \\ jose.maria.daga@upc.edu \\ * Correspondence: marc.marin@urv.cat
}

check for updates

Citation: Salueña Berna, X.; Marín-Genescà, M.; Dagà-Monmany, J.M. Analysis of Valorization Process of Aluminum Breakage Scraps to Obtain Green Hydrogen. Metals 2021, 11, 598. https://doi.org/10.3390/ met11040598

Academic Editor: Alexandre Chagnes

Received: 26 February 2021

Accepted: 4 April 2021

Published: 6 April 2021

Publisher's Note: MDPI stays neutral with regard to jurisdictional claims in published maps and institutional affiliations.

Copyright: (c) 2021 by the authors. Licensee MDPI, Basel, Switzerland. This article is an open access article distributed under the terms and conditions of the Creative Commons Attribution (CC BY) license (https:// creativecommons.org/licenses/by/ $4.0 /)$.

\begin{abstract}
In this article, it is proposed to use aluminum breakage scraps to obtain green hydrogen through the aluminum-water reaction with caustic soda as a catalyst with experimental research. From this exothermic reaction, both hydrogen and the heat generated can be used. Due to the low price of aluminum chips, this allows us to produce green hydrogen below the current price that is obtained using renewable energy sources and electrolyzers. We have also developed a process that is sustainable since it is obtained as alumina and caustic soda waste that can be reused. This alumina obtained, once filtered, has high purity which allows us to produce high-quality primary aluminum without the need to use bauxite and the production of red sludge is also reduced. A comparative study-analysis was carried out between two of the forms in which the most common aluminum is presented in industry to analyze which one performs better by studying key factors such as the hydrogen produced, and the waste generated during the process. Finally, the mathematical model has been defined to be able to control the flow based on different key parameters such as temperature, molarity, and geometry. Undoubtedly, the study that we present represents a milestone for the recovery of metallic aluminum waste and may be of great interest to industries that use aluminum in their processes, such as recuperators, as well as the vehicle and aerospace industries.
\end{abstract}

Keywords: metal waste valorization; aluminum breakage scrap; green hydrogen; hydrogencontrolled generation

\section{Introduction}

Different industries, such as heat treatments, synthesis of ammonia and hydrochloric acid, water treatments, and generators of electric energy using fuel cells, use hydrogen in their industrial processes and they could eventually be interested in not depending on distributors of industrial gases.

Furthermore, there is currently a lot of interest in producing green hydrogen, that is, without emitting $\mathrm{CO}_{2}$ [1]. The most widely used systems are those that use the electrolysis of water using renewable energies and electrolyzers [2]. The problem with these systems is that they depend on the price of electricity, the amount of hydrogen required, and the effectiveness of the electrolyzer, so the cost of hydrogen generated for medium-sized demand and for an efficiency greater than $60 \%$ is of the order USD $2.5-7 / \mathrm{kg} \mathrm{H}_{2}$ [3].

At present, various systems are being studied for obtaining hydrogen from the aluminum-water reaction [4]. The advantage of this method is the possibility of obtaining high purity hydrogen from aluminum waste [5], in a reactor located in the customer's own company, with no need of using high-pressure hydrogen storage tanks.

When studying whether this system is profitable, it is usually done from an energy point of view, assuming that aluminum is manufactured only to generate hydrogen. But, it is when it is obtained from the aluminum wastes that hydrogen is obtained. In this 
study, the economic aspect is more valued and it is interesting to note that the price of the aluminum machining chips ( USD 0.6/ kg (LME 2020)) is lower, compared not only to the first and second melt, but also to other types of aluminum scrap, so it could be used for green hydrogen production.

This system is also completely sustainable since $\mathrm{Al}_{2} \mathrm{O}_{3}$ can be converted into topquality aluminum with the contribution of renewable energy, avoiding the extraction, transport, and treatment of bauxite ore, which represents $5.6 \mathrm{kWh} / \mathrm{kg} \mathrm{Al}$, and the management of waste-treatment alkalis (red sludge).

One of the current experimental methods to obtain hydrogen from metallic liquid aluminum uses gallium or activated $\mathrm{Ga}-\mathrm{In}-\mathrm{Sn}-\mathrm{Bi}$ alloys with water, but the system requires preparation, is expensive, and the waste must be processed [6].

Another of the methods used to facilitate the aluminum-water reaction is to introduce aluminum into an alkaline solution to remove the surface oxide layer and subsequently the different layers of aluminum hydroxide created [7]. There are several cases of industrial prototypes where this technology is applied [8], although it is usually based on high purity aluminum powder, a size in the micron range, and very expensive [9], compared to machining chips. In such prototypes, the aluminum, which enters the reactor, is usually dosed to control the flow rate of hydrogen generated [10]. Generally, in industrial processes or fuel cells, the flow rate is to be constant over time, to stop the flow in case of a shutdown, or to increase it in case of increased production [11].

From a technological point of view to dose a solid, especially in the form of a chip, is more difficult than to dose a liquid [12]. That is why a system that doses liquid is preferred. On the other hand, when the aluminum chip is in contact with water in an alkaline medium, a constant flow of hydrogen is not produced. Initially, a very high flow rate is obtained, and it decreases as time passes [13]. When a certain flow is needed, a reservoir is required to store part of the initial hydrogen or the remainder in the event of a shutdown when operating. This reservoir could be avoided or reduced with a system that generates the exact required flow and that could react almost immediately in the case of a stop, as is the case with the one proposed in this study. Another drawback of the aluminum-water reaction in the alkaline medium is that, although the hydrogen obtained is of high purity, it usually sweeps along some particles of sodium hydroxide $(\mathrm{NaOH})$ and water vapor [14], which often makes filtering difficult.

The aluminum is to be introduced into a reactor and the sodium hydroxide solution will be dosed to achieve the required hydrogen flow rate. A very common way of proceeding with this type of process is to flood part of the reactor with the $\mathrm{NaOH}$ solution [15]. In this type of system, the hydrogen flow rate is hardly constant [16], with the risk that in case of a shutdown, when the liquid is removed from the reactor, aluminum hydroxide plates may appear on the wetted surface of aluminum, which slows down the restart of a new reaction and makes it more difficult [17]. Besides, a blockage in the liquid outlet from the reactor, due, for example, to aluminum chips, other metals, or crystallized aluminum hydroxide, could force the reaction to occur, the production of hydrogen would be in excess and therefore the reactor could be damaged due to overpressure [18].

This research proposes a method for obtaining hydrogen from aluminum chips in a controlled manner in an alcoholic medium with isopropyl alcohol, by dosing sodium hydroxide solution (7.5 M) [19]. A theoretical-experimental model will be proposed to define the hydrogen flow rate as a function of the size of the chip, the active surface, the molarity, and the temperature of the solution. The way the alcohol affects the reaction will also be described. A comparative study of the hydrogen flow rates obtained with different types of machining chips, as well as the performance of the reaction, will also be carried out. Finally, the purity of the hydrogen and the derived by-product, alumina $\left(\mathrm{Al}_{2} \mathrm{O}_{3}\right)$, will be analyzed. 


\section{Materials and Methods}

\subsection{Aluminum}

\subsubsection{Aluminum Plate (A1)}

To get the theoretical-experimental model, a $0.5 \mathrm{~mm}$ thick aluminum plate was used, according to ISO 209: 2007 Al 99.5 and whose characteristics are shown in Table 1.

Table 1. Designation and composition of aluminum ISO 209 Al 99.5 of the plate.

\begin{tabular}{cccccccc}
\hline Aluminum & $\mathbf{S i}(\%)$ & $\mathbf{C u}(\%)$ & $\mathbf{Z n}(\%)$ & $\mathbf{F e}(\%)$ & $\mathbf{M n}(\%)$ & Others (\%) & Al(\%) \\
\hline A1 & 0.25 & 0.05 & 0.1 & 0.4 & 0.05 & $<0.05$ & 99.5 \\
\hline
\end{tabular}

\subsubsection{Aluminum Chips (A2 and A3)}

To carry out the comparative study of the aluminum chips from the industry, turning chips of approximately $20 \times 5 \times 0.5 \mathrm{~mm}^{3}$ were selected, being A2-aluminum chips from the automotive industry and A3-aluminum chips from the aeronautical industry, whose characteristics are shown in Table 2.

Table 2. Designation and composition of aluminum chips from the automotive industry (A2) and the aeronautical industry (A3).

\begin{tabular}{cccccccc}
\hline Aluminum & SI (\%) & Cu (\%) & Zn (\%) & Fe (\%) & Mn (\%) & Others (\%) & A1 (\%) \\
\hline A2 & 5 & 1.5 & 0.7 & 0.5 & 0.15 & $<0.05$ & 92 \\
\hline A3 & 0.5 & 1 & 5 & 0.2 & 0.1 & $<0.05$ & 94 \\
\hline
\end{tabular}

\subsubsection{Pure Grainy Aluminum (A4)}

It was necessary to use pure grainy aluminum with a diameter of less than $1 \mathrm{~mm}$ as a reference in the results since it is not affected by passivation due to its size, purity, and shape. Also, this was used as a reference to evaluate the results of the purity of the waste, aluminum hydroxide (PANREAC 141098.1611). Its characteristics are shown in Table 3.

Table 3. Designation and composition of pure grainy aluminum taken as reference (A4).

\begin{tabular}{cccccccc}
\hline Aluminum & Si (\%) & Cu (\%) & Zn (\%) & Fe (\%) & Mn (\%) & Others (\%) & Al (\%) \\
\hline A4 & - & - & - & - & - & $<0.05$ & 99.7 \\
\hline
\end{tabular}

\subsection{Sodium Hydroxide}

The study was carried out with solutions of sodium hydroxide $7.5 \mathrm{M}$, from $50 \%$ solutions (PANREAC 142404.0716) and distilled water.

\subsection{Alcohol}

The alcohol used was 99\% isopropyl alcohol. Its characteristics are shown in Table 4.

Table 4. Designation and composition of alcohol used in the tests.

\begin{tabular}{ccccc}
\hline Alcohol (99\%) & Formula & $\mathrm{T}_{\text {boiling }}\left({ }^{\circ} \mathrm{C}\right)$ & Density $\left(\mathrm{g} / \mathrm{cm}^{3}\right)$ at $2{ }^{\circ} \mathrm{C}$ & Solubility in $\mathrm{H}_{\mathbf{2}} \mathrm{O}$ \\
\hline Isopropyl alcohol & $\mathrm{C}_{3} \mathrm{H}_{8} \mathrm{O}$ & 83 & 0.79 & miscible \\
\hline
\end{tabular}

It is important to highlight that the boiling temperature of the alcohol has to be higher than $60{ }^{\circ} \mathrm{C}$ since the optimum aluminum-water reaction temperature is $60{ }^{\circ} \mathrm{C}$ [20] and therefore the control of these vapors in the condenser becomes easier. 


\section{Components and Methodology Used in Tests \\ Determining the Theoretical Model}

A test was carried out to find the theoretical model, to know how aluminum chips react in a $7.5 \mathrm{M}$ caustic soda solution, with and without isopropyl alcohol. As shown in Figure 1, the test was carried out with the following components-a $500 \mathrm{~mL}$ flask with one outlet, hermetically sealed, and with the outlet connected to a calibrated test tube, filled with water, by a silicone tube; a heater to maintain the double boiler temperature at $25^{\circ} \mathrm{C}$ in one of the tests and $60^{\circ} \mathrm{C}$ in the other one; a calibrated test tube to evaluate the volume of hydrogen produced; and a chronometer to calculate the flow rate.

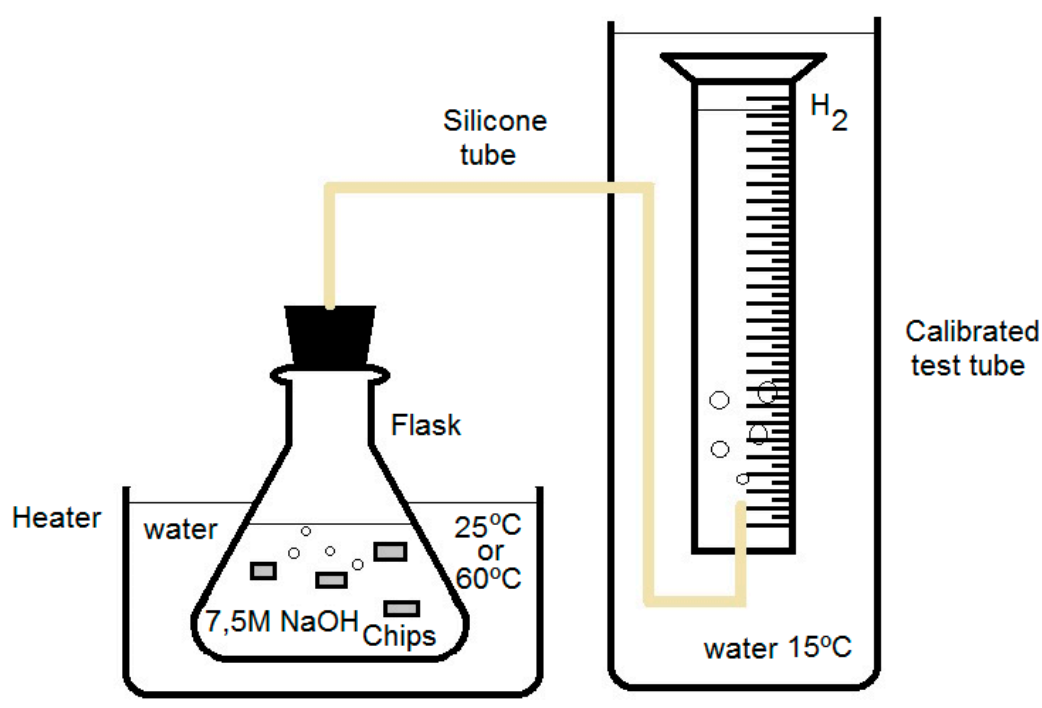

Figure 1. Draft of the experimental equipment used for the theoretical-model-determination test.

The selected aluminum was always of type A1 (according to Table 1), all tests being carried out in the same way. The water was first heated to a test temperature of $25^{\circ} \mathrm{C}$ or $60{ }^{\circ} \mathrm{C}$ in a $200 \mathrm{~mL} 7.5 \mathrm{M} \mathrm{NaOH}$ solution (with or without $100 \mathrm{~mL}$ of isopropyl alcohol, according to the test) in a double boiler or water bath heater. Then, the aluminum samples were introduced into the flask while keeping the temperature constant, and the flask was capped to make it airtight. The aluminum reacted with the solution and some hydrogen was generated. The hydrogen was led to a calibrated test tube by a silicone tube. The volume of generated hydrogen was measured every minute, at a temperature of $15^{\circ} \mathrm{C}$. The test ended when all the aluminum was consumed. Two tests were performed with each sample, the mean values were obtained, and the measurement repeated if the variation exceeded $10 \%$. In some tests, the thickness of the chips were measured every minute with a centesimal micrometer (expanded uncertainty $\mathrm{U}=0.005 \mathrm{~mm}$ ).

\section{Tests}

\subsection{Test 1: Effect of Chips Size}

In test 1 two experiments were carried out to compare the generation of hydrogen by a reaction of water-aluminum (A1) in a $7.5 \mathrm{M} \mathrm{NaOH}$ solution, at $25^{\circ} \mathrm{C}$ in plate (sheet) or chip (bit)format. A $20 \times 30 \times 0.5 \mathrm{~mm}^{3}$ plate was first tested and then a set of 104 chips of $2 \times 2 \times 0.5 \mathrm{~mm}^{3}$ was also tested so that in both tests both samples had the same initial contact surface $\left(1240 \mathrm{~mm}^{2}\right)$, see Table 5 .

A chip thickness of $0.5 \mathrm{~mm}$ was chosen since it is usually the one chosen in finishing machining and as will be seen later, it does not influence the active surface. An increase in this value would increase the reaction time but would not significantly vary the flow achieved. 
Table 5. A1 plate and chip features.

\begin{tabular}{ccccc}
\hline Typology & Quantity & $\begin{array}{c}\text { Dimensions } \\
\left(\mathbf{m m}^{\mathbf{3}}\right)\end{array}$ & $\begin{array}{c}\text { Weight } \\
\mathbf{( g )}\end{array}$ & $\begin{array}{c}\text { Initial Contact Surface } \\
\left(\mathbf{m m}^{\mathbf{2}}\right)\end{array}$ \\
\hline Plates (sheets) & 1 & $20 \times 30 \times 0.5$ & 0.788 & 1240 \\
\hline Chips (bits) & 104 & $2 \times 2 \times 0.5$ & 0.534 & 1240 \\
\hline
\end{tabular}

\subsection{Test 2: Temperature Effect}

In test 2 the effect of temperature on hydrogen flow generation was compared. As verified in the previous test, the reaction time depended on the plate thickness regardless of the shape of the plates or chips. Therefore, a $20 \times 30 \times 0.5 \mathrm{~mm}^{3}$ plate was used for the test, and the temperature effects were experienced at $25^{\circ} \mathrm{C}$ and $60^{\circ} \mathrm{C}$.

\subsection{Test 3: Effect of Adding Alcohol}

In test 3 the effect of adding isopropyl alcohol in the $\mathrm{NaOH}$ solution was compared. A $20 \times 30 \times 0.5 \mathrm{~mm}^{3}$ aluminum plate was used at $60^{\circ} \mathrm{C}$ with and without propyl alcohol. This allowed us to see the effects of the addition of alcohol.

\section{Hydrogen Generation Reactor from Chips}

\subsection{Hydrogen Generation Procedure}

Hydrogen generation was carried out by using a covered 20-L reactor in glass, using water at $60^{\circ} \mathrm{C}$ as a heating fluid throughout the experiment to maintain the inside temperature between $60^{\circ} \mathrm{C}$ and $65^{\circ} \mathrm{C}$. As shown in Figure 2, the A2 and A3 aluminum chips were introduced together with enough alcohol to cover them, namely $100 \mathrm{~mL}$. The reactor was fed with a $7.5 \mathrm{M}$ sodium hydroxide solution at a constant flow rate of $10 \mathrm{~mL} / \mathrm{min}$ through a Heidolph PD-5001 one head peristaltic pump with a silicone tube of 6.3/9.5 mm diameter. The hydrogen generated in the aluminum-water reaction was circulated by a water-cooled condenser to remove any alcohol vapors. To ensure that hydrogen did not carry alcohol, it was passed through a water filter. The hydrogen was filtered with a silica gel trap to remove any remaining moisture and the flow rate was subsequently measured with a volumetric gas meter. Both the sodium hydroxide solution flow rate and the weight of the aluminum chips as well as the amount of alcohol were specified in each of the tests performed.

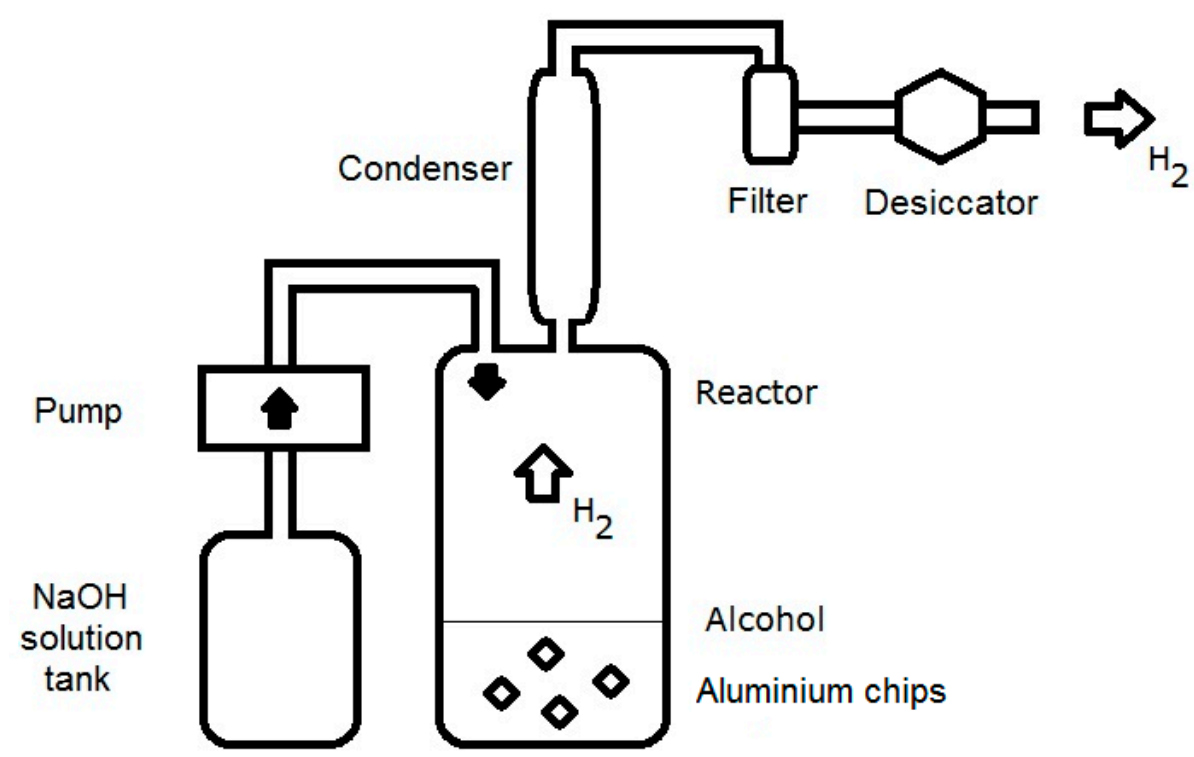

Figure 2. Draft of the experimental equipment used for the production of hydrogen. 
The hydrogen flow rate was measured using a RITTER TG20/6 (Bochum, Germany) volumetric gas meter, time readings were also carried out for every liter, and the total volume of hydrogen generated was set. The objective of the experiment was to compare the results obtained with each one of these two types of chips to choose the most suitable one for hydrogen generation.

\subsection{Analysis of Hydrogen Purity}

To determine the hydrogen purity, several samples of one liter of hydrogen generated from aluminum A2 were collected in a Tedlar bag after purging the gas. The hydrogen obtained was then analyzed by an "Agilent 3000 " gas microchromatograph with three independent modules with a thermal conductivity detector (TCD) and columns for measuring light gases (molecular sieve), light hydrocarbons (plot U), and oxygen compounds (Stabilwax). The analysis was carried out by directly injecting the sample into the equipment and obtaining the results from a calibration of the equipment from $99.999 \%$ pure hydrogen. Three tests were performed for each of the samples collected.

\subsection{Analysis of Aluminum Hydroxide Purity}

To find the aluminum hydroxide purity, several samples of sodium tetrahydroxyaluminate were collected and precipitated as $\mathrm{Al}(\mathrm{OH})_{3}$ with hydrochloric acid. Subsequently, they were cleaned to eliminate any trace of soluble salts that might have formed during the reaction with the acid. The samples were then dried in an oven at $1000{ }^{\circ} \mathrm{C}$, for $30 \mathrm{~min}$, to obtain $\mathrm{Al}_{2} \mathrm{O}_{3}$, and finally, the purity of the aluminum oxide obtained was analyzed by a mass spectrometer in an external laboratory.

\section{Theoretical Kinetic Model}

\subsection{Chemical Reactions}

A diffusion phenomenon occurs on the Al-NaOH surface. We will address this phenomenon from a chemical point of view. The reaction to obtain hydrogen from aluminum and water [21] is given by Equation (1).

$$
\begin{gathered}
\mathrm{Al}(\mathrm{s})+3 \mathrm{H}_{2} \mathrm{O}(\mathrm{l}) \rightarrow \mathrm{Al}(\mathrm{OH})_{3}(\mathrm{~s})+3 / 2 \mathrm{H}_{2}(\mathrm{~g}) \\
\Delta \mathrm{H}=-278 \mathrm{~kJ} / \mathrm{mol} \mathrm{H}_{2}
\end{gathered}
$$

Since the aluminum hydroxide is solid, it creates a surface layer that prevents water from reacting with aluminum, so it makes it inactive. To prevent inactivity, the reaction must be carried out with an alkaline solution $(\mathrm{NaOH})$ so that the aluminum hydroxide is converted into aqueous sodium tetrahydroxyaluminate according to Equation (2).

$$
\mathrm{Al}(\mathrm{OH})_{3}(\mathrm{~s})+\mathrm{NaOH}(\mathrm{aq}) \rightarrow \mathrm{NaAl}(\mathrm{OH})_{4}(\mathrm{aq})
$$

To formulate the kinetic model, it is assumed initially, as a hypothesis, that there will be enough aluminum active surface area, which reacts with water so that the hydrogen flow rate depends exclusively on the added water flow rate [19]. This hypothesis will be used only as a starting point for the study since this area might be reduced by the partial inactivity of the area due to the appearance of aluminum hydroxide in the form of bayerite [22]. Furthermore, in our case, this is more noticeable in the case of chips than in the case of grains, since the contact with the sodium hydroxide is lower because of the shape, and therefore, also, the reaction to get sodium tetrahydroxyaluminate according to the Equation (2) is lower. This active surface decreases as time passes since the aluminum is transformed into aluminum hydroxide, depending also on the geometric shape of the original product. The originality of this study is that this surface has been modeled for the simple prismatic chip shape. Finally, based on the experimental data, what the active surface should be is calculated so that the limiting reactant is water, or aluminum, in the hydrogen output. 


\subsection{Theoretical Hydrogen Flow}

\subsubsection{The Hypothesis of Enough Active Aluminum Surface}

The theoretical hydrogen flow rate $\mathrm{Q}_{\mathrm{H} 2, \mathrm{t}}$ obtained according to Equation (1), for any aluminum shape, as a function of the water flow rate, $\mathrm{Q}_{\mathrm{H} 2 \mathrm{O}}$, with a density of $\rho_{\mathrm{H} 2 \mathrm{O}}$ and an atomic weight of water of $\mathrm{M}_{\mathrm{H} 2 \mathrm{O}}$, can be written according to Equation (3), assuming an ideal gas performance [20]. The fundamental hypothesis is because there is enough active aluminum surface.

$$
\mathrm{Al}(\mathrm{OH})_{3}(\mathrm{~s})+\mathrm{NaOH}(\mathrm{aq}) \rightarrow \mathrm{Na} \mathrm{Al}(\mathrm{OH})_{4}(\mathrm{aq})
$$

\subsubsection{The Hypothesis of Not Enough Active Aluminum Surface}

The theoretical hydrogen flow rate, $\mathrm{Q}_{\mathrm{H} 2, \mathrm{t}}$, obtained according to Equation (1), for a sufficient water flow rate, as a function of the aluminum active surface, $S_{\mathrm{Al}, t}$, the reduction of thickness as a function of time, $e$, the density, $\rho_{\mathrm{Al}}$, and the atomic weight, $\mathrm{M}_{\mathrm{Al}}$, can be written approximately according to Equation (4), assuming an ideal gas performance [20]. The fundamental hypothesis is since there is not enough active aluminum surface to react with the supplied water flow.

$$
\mathrm{Q}_{\mathrm{H} 2, \mathrm{t}} \approx \frac{3}{2} \frac{\rho_{\mathrm{Al}}}{\mathrm{M}_{\mathrm{Al}}}\left(\frac{\mathrm{RT}}{\mathrm{P}}\right)\left(\mathrm{S}_{\mathrm{Al}, \mathrm{t}} \cdot \mathrm{e}\right)
$$

\subsection{Active Aluminum Surface}

\subsubsection{Aluminum Waste in the Grainy Form}

When the waste is grain-shaped, the particles are considered to be spheres of radius $R$, of the same size, and it is assumed that the aluminum alloy is homogeneous with purity $\eta$ and density, $\rho_{\mathrm{Al}}$. The depletion of the radius is assumed to be constant as a function of time, its active surface being a function of the initial aluminum mass, $\mathrm{W}_{\mathrm{Al}, 0}$, and time, according to Equation (5) described and developed in the bibliography [23].

$$
\mathrm{S}_{\mathrm{Al}, \mathrm{t}}=\left(\frac{3 \mathrm{~W}_{\mathrm{Al}, 0 \eta}}{\rho_{\mathrm{Al}}}\right) \frac{\mathrm{R}_{\mathrm{t}}^{2}}{\mathrm{R}_{0}^{3}}
$$

\subsubsection{Aluminum Waste in Chip Shape}

Assuming that the chip is an ideally prismatic shape, a model that describes the active aluminum chip surface as a function of time has been developed.

If we consider an aluminum machining chip with dimensions: $L \cdot a \cdot p$, where " $p$ " is the cutting depth, "a" is the feed, and " $\mathrm{L}$ " is the length (Figure 3), and assuming, as assumed in the previous section, that there is a constant reduction of the surface thickness, $e$, as a function of time (in minutes), the depletion of the chip will be a function of time $t$ (in minutes) and will be applied on all surfaces of the chip until the thickness, $p$, is consumed, which will always be the smaller dimension.

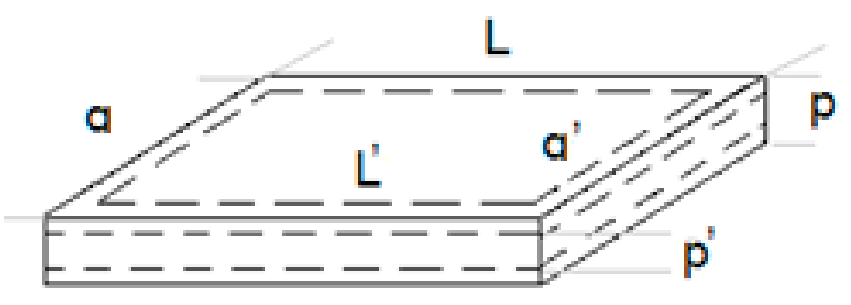

$$
\begin{aligned}
& L^{\prime}=L-2 \text { e.t } \\
& a^{\prime}=a-2 \text { e.t } \\
& p^{\prime}=p-2 \text { e.t }
\end{aligned}
$$

Figure 3. Theoretical representation of the thickness depletion, " $\mathrm{e}$ ", as a function of time, " $\mathrm{t}$ ", of a machining chip due to the aluminum-water reaction. 
The active surface as a function of the initial aluminum mass, purity, and density are described according to Equation (6).

$$
\mathrm{S}_{\mathrm{Al}, \mathrm{t}}=\frac{2 \mathrm{~W}_{\mathrm{Al}, 0} \eta}{\rho_{\mathrm{Al}} \mathrm{L} \text { a p }}[4 \mathrm{et}(3 \mathrm{et}-(\mathrm{L}+\mathrm{a}+\mathrm{p}))+\mathrm{L} \mathrm{p}+\mathrm{L} \mathrm{a}+\mathrm{pa}]
$$

Experimental confirmation of this formula was carried out, by introducing prismatic aluminum A1 chips (see Table 1), with dimensions $20 \times 30 \times 0.5 \mathrm{~mm}^{3}$ in a $7.5 \mathrm{M} \mathrm{NaOH}$ solution, keeping a constant temperature at the water bath. As the reduction of the thickness depends on the temperature, this has been analyzed at $25^{\circ} \mathrm{C}$ and $60^{\circ} \mathrm{C}$, and it has been concluded that the calculated active surface exactly matches the experimental active surface, and it is linearly reduced [22]. The experimental average reduction or depletion is shown in Table 6.

Table 6. Reduction of aluminum A1 thickness as a function of temperature in $7.5 \mathrm{M} \mathrm{NaOH}$.

\begin{tabular}{cc}
\hline Temperature $\left({ }^{\circ} \mathbf{C}\right)$ & Thickness Reduction $(\mathbf{m m} / \mathbf{m i n})$ \\
\hline 25 & $0.00117 \pm 0.00003$ \\
\hline 60 & $0.01473 \pm 0.00003$ \\
\hline
\end{tabular}

Of course, the lifetime of the chip, from the time it begins to react until it is completely consumed, depends on its smaller dimension, i.e., its thickness, $p$. Since the thickness of the chip is very small, the reduction of the upper and lower faces, L.a, is minor, so that the active surface would go from a noteworthy value to zero abruptly, when the thickness $\mathrm{p}^{\prime}=\mathrm{p}-$ 2et equals zero. This happens gradually since in the last phase the chip floats and disappears from the ends towards the center. The exact flow rate obtained as a function of time $\mathrm{Q}_{\mathrm{H} 2, \mathrm{t}}$, improving Equation (4), is determined by Equation (7).

$$
\mathrm{Q}_{\mathrm{H} 2, \mathrm{t}}=\frac{3}{2} \frac{\rho_{\mathrm{Al}}}{\mathrm{M}_{\mathrm{Al}, \mathrm{t}}}\left(\frac{\mathrm{RT}}{\mathrm{P}}\right)\left(\mathrm{S}_{\mathrm{Al}, \mathrm{t}} \cdot \mathrm{e}-4 \mathrm{e}^{2}((\mathrm{p}-2 \mathrm{et})+(\mathrm{a}-2 \mathrm{et})+(\mathrm{L}-2 \mathrm{et})-2 \mathrm{e})\right)
$$

where the total theoretical volume of hydrogen, $\mathrm{V}_{\mathrm{H} 2}$, obtained at a time $t=\mathrm{n}$ (minutes) is given by Equation (8):

$$
\mathrm{V}_{\mathrm{H} 2}=\frac{3}{2} \frac{\rho_{\mathrm{Al}}}{\mathrm{M}_{\mathrm{Al}}}\left(\frac{\mathrm{RT}}{\mathrm{P}}\right) \sum_{t=0}^{n}\left(\mathrm{~S}_{\mathrm{Al}, \mathrm{t}} \cdot \mathrm{e}-4 \mathrm{e}^{2}((\mathrm{p}-2 \mathrm{et})+(\mathrm{a}-2 \mathrm{et})+(\mathrm{L}-2 \mathrm{et})\right.
$$

\section{Results and Discussion}

\subsection{Result of Test 1: Effect of Chips Size}

The generation of hydrogen from one single sheet was studied in the first test, and 104 A1 aluminum chips with the same initial active surface area were studied in the second test. In both cases, the surface was $1240 \mathrm{~mm}^{2}$, in a $7.5 \mathrm{M} \mathrm{NaOH}$ solution (without alcohol) at a water bath temperature of $25^{\circ} \mathrm{C}$. The result of the tests are shown in Figure 4 , as well as the theoretical values according to Equation (8).

Figure 4 shows how the hydrogen flow was constantly, approximately 5 to $4 \mathrm{~mL} / \mathrm{min}$, generated in the plate, while it decreased in the chips. This fact, as seen in Figure 5, is because the active surface is reduced faster in the chips than in the sheet. Initially, for both types, there was enough active aluminum surface so that the restricting element was the flow rate of water in contact and the generated hydrogen flow follows Equation (3). In the case of using chips, after about $30 \mathrm{~min}$, the active surface is lower than the critical surface and the hydrogen flow then follows Equation (7), where the restricting element is aluminum. It was also observed that the reaction time depended on the thickness, $p$, either in the sheet or in the chip format. Therefore, it is important to know the instantaneous active surface to calculate the hydrogen flow rate that can be generated. 


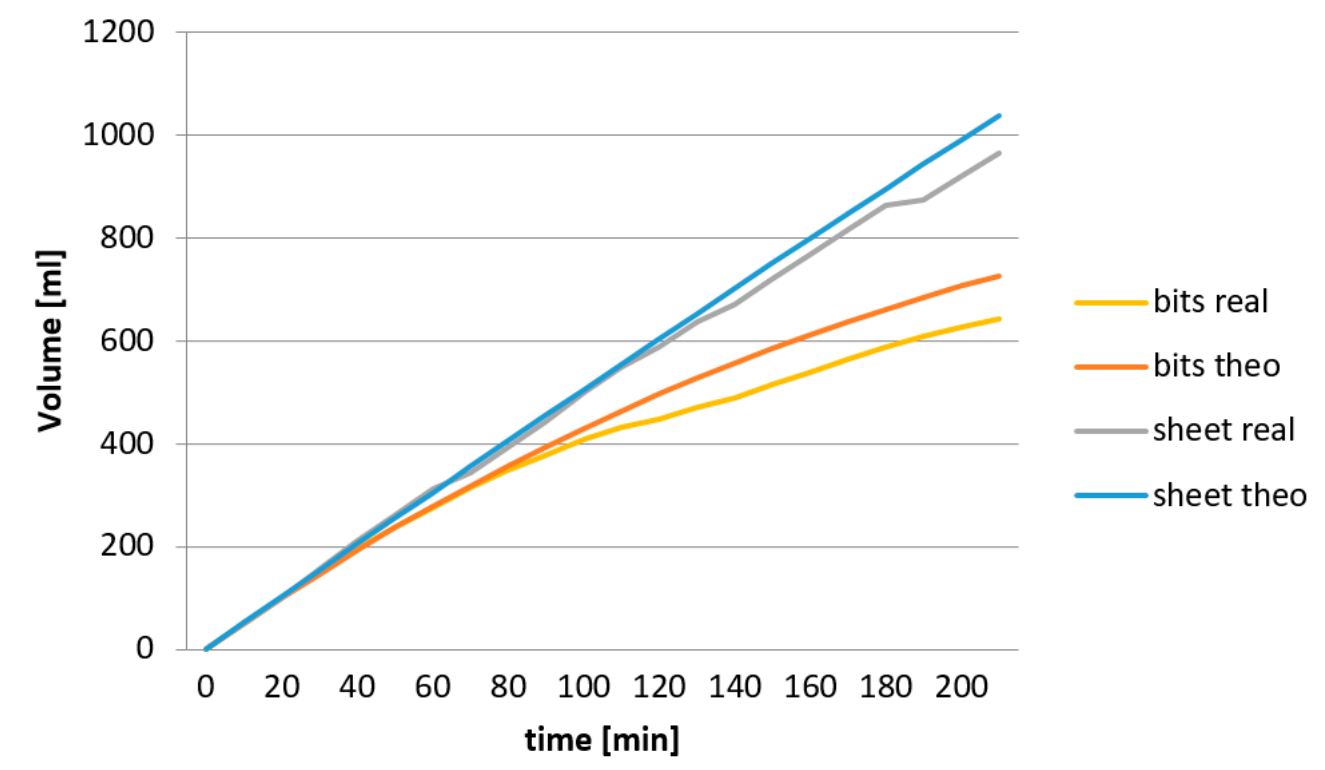

Figure 4. Comparison of the hydrogen volume generated from 104 sheet metal chips of $2 \times 2 \times 0.5 \mathrm{~mm}^{3}$ (bits) and a plate of $20 \times 30 \times 0.5 \mathrm{~mm}^{3}$ (sheet) of aluminum A1, of the same initial active surface $1240 \mathrm{~mm}^{2}$ in a $7.5 \mathrm{M} \mathrm{NaOH}$ (non-alcohol) solution at a bath temperature of $25^{\circ} \mathrm{C}$.

The active aluminum surface, given in Equation (6), is shown in Figure 5.

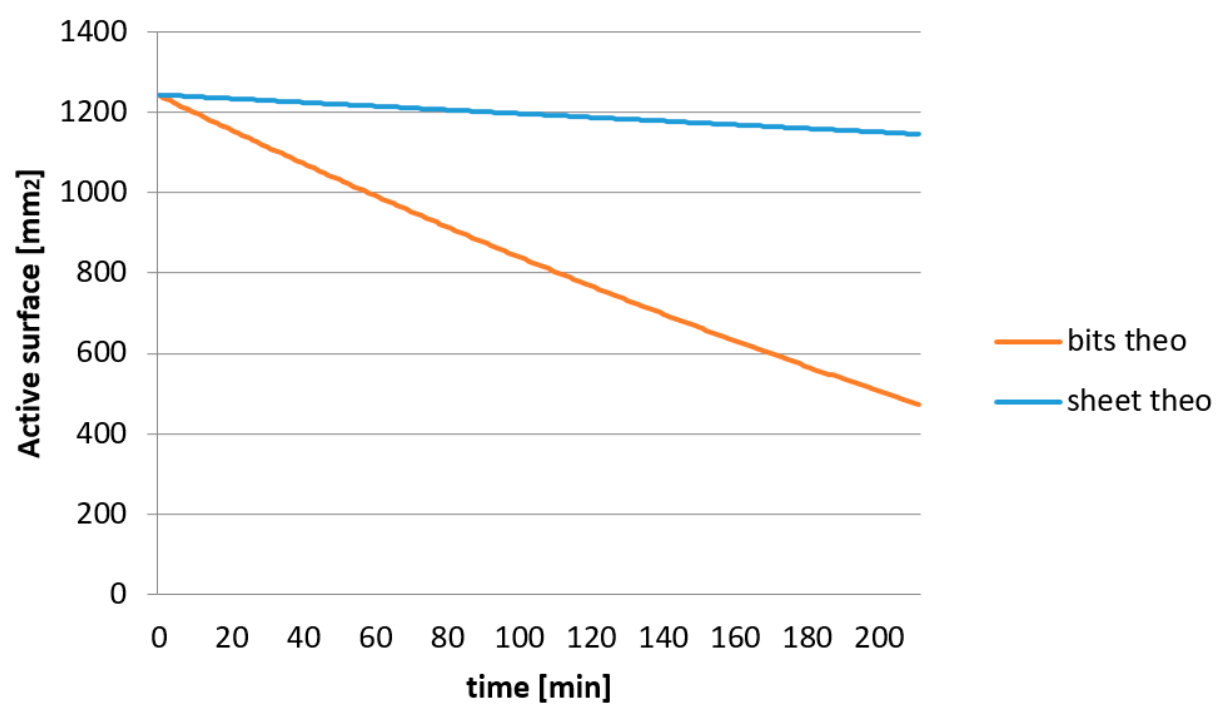

Figure 5. Comparison of the theoretical active aluminum surface for 104 sheet metal chips of $2 \times 2 \times 0.5 \mathrm{~mm}^{3}$ (bits) and a plate (sheet) of aluminum A1 of $20 \times 30 \times 0.5 \mathrm{~mm}^{3}$.

\subsection{Result of Test 2: Temperature Effect}

Figure 6 shows how temperature affects the hydrogen generation reaction tested on a sheet of $\mathrm{Al}$ in a water bath at $25^{\circ} \mathrm{C}$ and $60{ }^{\circ} \mathrm{C}$, compared to those theoretically obtained in Equation (8). It should be noted that the temperature of measurement of the hydrogen flow rate was $15^{\circ} \mathrm{C}$, and therefore, this is the temperature to be entered in that equation.

The temperature directly affected the thickness, $e$, depletion as shown in Table 7, so the flow rate was much higher at $60^{\circ} \mathrm{C}$. 


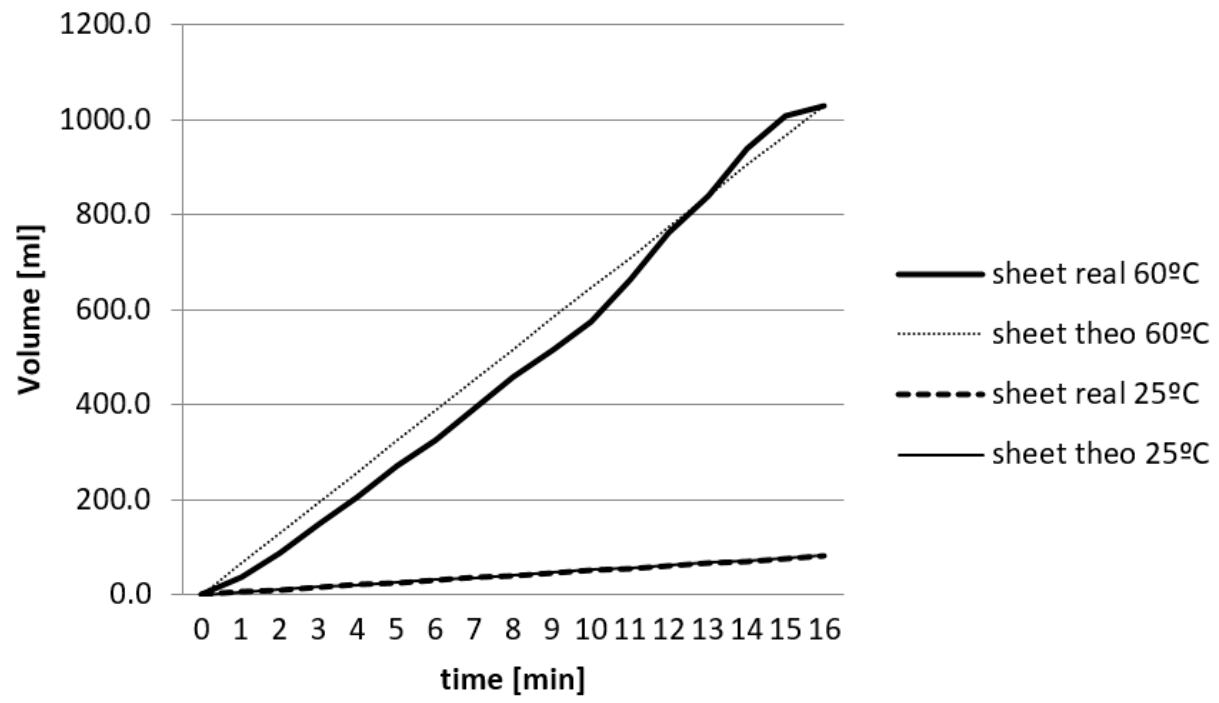

Figure 6. Comparison of the hydrogen volume generated from an aluminum sheet of $20 \times 30 \times 0.5 \mathrm{~mm}^{3}$ (sheet) in a $7.5 \mathrm{M} \mathrm{NaOH}$ solution (without alcohol), at a bath temperature of $60{ }^{\circ} \mathrm{C}$ and $25^{\circ} \mathrm{C}$.

Table 7. Comparison of the effect of temperature on hydrogen generation.

\begin{tabular}{ccccc}
\hline $\begin{array}{c}\text { Aluminum A1 Sheet } \\
\left(\mathbf{m m}^{\mathbf{3}}\right)\end{array}$ & $\begin{array}{c}\text { Temperature } \\
\left({ }^{\circ} \mathbf{C}\right)\end{array}$ & $\begin{array}{c}\text { Thickness Depletion e } \\
(\mathbf{m m} / \mathbf{m i n})\end{array}$ & $\begin{array}{c}\text { Time } \\
(\mathbf{m i n})\end{array}$ & $\begin{array}{c}\text { Average Flow Rate } \\
(\mathbf{m L} / \mathbf{m i n})\end{array}$ \\
\hline $20 \times 30 \times 0.5$ & 25 & $0.00117 \pm 0.00003$ & 208 & 4.7 \\
\hline $20 \times 30 \times 0.5$ & 60 & $0.01473 \pm 0.00003$ & 16 & 64.3 \\
\hline
\end{tabular}

\subsection{Result of Test 3: Effect of Adding Alcohol}

Figure 7 shows the comparison of the flow experimentally obtained by the addition of isopropyl alcohol in the $\mathrm{NaOH}$ solution with that obtained without alcohol. An aluminum sheet of $20 \times 30 \times 0.5 \mathrm{~mm}^{3}$ was used, at $60{ }^{\circ} \mathrm{C}$ with and without isopropyl alcohol.

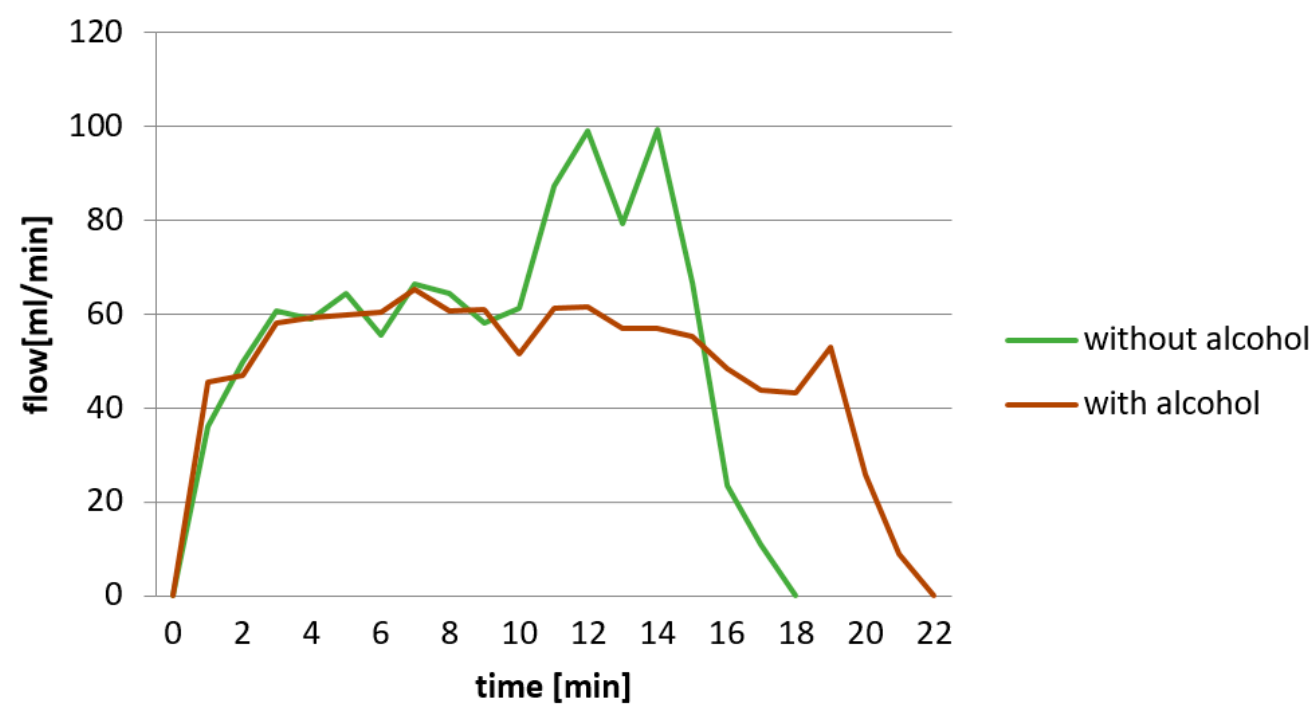

Figure 7. Comparison of the hydrogen flow rate generated from an aluminum A1 sheet of $20 \times 30 \times 0.5 \mathrm{~mm}^{3}$ in a $7.5 \mathrm{M} \mathrm{NaOH}$ solution, with and without isopropyl alcohol in a water bath at $60^{\circ} \mathrm{C}$. 
As the alcohol has a lower density than the $\mathrm{NaOH} 7.5 \mathrm{M}$ solution, two layers or phases are formed initially [24], and the sheet stays submerged in the $\mathrm{NaOH}$ solution at $60^{\circ} \mathrm{C}$. As the temperature increases, the flow rate increases too, and the aluminum-water reaction is exothermic, but since there are two phases, the temperature remains constant. Therefore, when the sheet floats to the interface due to the loss of thickness, the flow rate does not increase, but it remains constant. In the absence of alcohol in the upper zone of the solution, the temperature increases to $65^{\circ} \mathrm{C}$ due to the reaction (although the bath remains at $60{ }^{\circ} \mathrm{C}$ ), and then the flow rate also increases. In industrial processes, the flow rate should always be as constant as possible, and the alcohol helps to achieve it. When the sheet was so thin as to float in the alcohol, the reaction slowed down and the sheet was not consumed until $16 \mathrm{~min}$ later, generating an insignificant flow. Another advantage of using the alcohol is that the reaction is less active, as the sheet floats away from the interface, between the $\mathrm{NaOH}$ solution and the alcohol phase. Therefore, the reaction can be stopped by controlling the level of alcohol so that the aluminum is immersed in it. Finally, the alcohol acts as a filter by not allowing the hydrogen to seep along any $\mathrm{NaOH}$ particles.

\subsection{Results in the Hydrogen Generation Reactor from Different Types of Industrial Aluminum Chips}

Figure 8 shows the results obtained by reacting different types of chips obtained by machining different aluminum used in the industry, with the $7.5 \mathrm{M}$ solution and isopropyl alcohol in the reactor. Those chips were those of automotive aluminum A1 and aeronautical aluminum A2. The same mass of pure granule aluminum A3, with a large active surface, was also reacted, and it was taken as a reference.

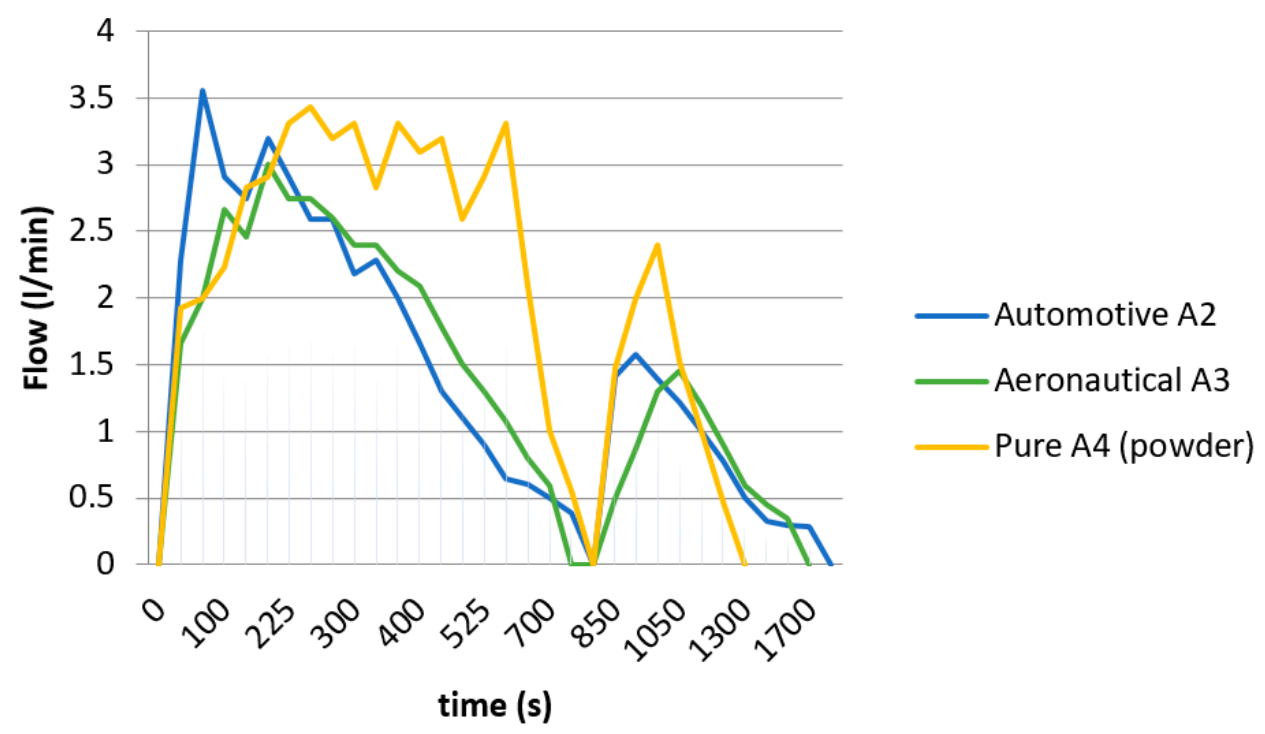

Figure 8. Comparison of the hydrogen flow generated by automotive aluminum chips A2 and aeronautical aluminum chips A3 in alcoholic medium, and isopropyl alcohol, starting from $30 \mathrm{~g}$ of aluminum and dosing $10 \mathrm{~mL} / \mathrm{min}$ of $7.5 \mathrm{M}$ sodium hydroxide solution, at a bath temperature of $60{ }^{\circ} \mathrm{C}$ in the reactor. These are compared to the pure granulated aluminum A4 (powder), used as a reference, under the same conditions.

It was seen that in the case of chips, the results obtained for pure aluminum with a large surface area, were initially exceeded. This fact was caused by the appearance of impurities in the chips due to the oxides of the components of their alloys [25], which makes the reaction between aluminum and water easier as they cause "paths" in the oxide or aluminum hydroxide layers formed on the aluminum surface. These paths facilitate the introduction of water through the inactive surface layers, and therefore its contact with aluminum. 
After the initial phase, hydrogen flow rates of about $3 \mathrm{~L} / \mathrm{min}$ were reached, both by using chips and granulate aluminum. This flow corresponded approximately to the one generated from $5.4 \mathrm{~mL} / \mathrm{min}$ of water $(10 \mathrm{~mL} / \mathrm{min}$ of $7.5 \mathrm{M} \mathrm{NaOH})$ assuming enough aluminum active surface, i.e., according to Equation (3), of $3.5 \mathrm{~L} / \mathrm{min}$. This difference in flow was due to the decrease of the contact surface between the $\mathrm{NaOH}$ solution and the aluminum surface because of the interaction of isopropyl alcohol.

The generated hydrogen flow decreased $250 \mathrm{~s}$ after the reaction has started, when using chips, due to the decrease of the active surface. This did not occur when using granules, with a larger active surface. When using granules, the flow rate remained constant.

The feed of $\mathrm{NaOH}$ solution was stopped $550 \mathrm{~s}$ after the reaction had started, by stopping the pump, to check if it was possible to quickly stop the generation of hydrogen by stopping the feed, and the result was affirmative.

When the reaction restarted, the same flow rate corresponding to the active surface before the interruption was obtained, and only $1.5 \mathrm{~L} / \mathrm{min}$ were reached, and it progressively decreased until the aluminum was completely consumed. Since the chips had a larger thickness than the granulated aluminum, the reaction lasted a few seconds longer than the one with the pure aluminum taken as a reference, ending after about $1700 \mathrm{~s}$. Afterwards, a solution of sodium hydroxide, without alcohol, was added to the remaining aluminum wastes that floated on the alcohol, and it was left for several hours to quantify all the hydrogen that could be extracted from each type of aluminum.

Table 8 shows the hydrogen obtained in the different cases. In the first column, the resulting hydrogen volume is shown after adding $100 \mathrm{~mL}$ of $7.5 \mathrm{M}$ sodium hydroxide solution in an alcoholic medium and waiting for the reaction to stop. In the second column, the volume of hydrogen obtained is shown after adding another $100 \mathrm{~mL}$ of $7.5 \mathrm{M}$ sodium hydroxide solution in an alcoholic medium, i.e., too much solution, and waiting for the reaction to stop (that is to say, waiting until the process ended). In the third column, the total volume of hydrogen obtained is shown, emptying the reactor but leaving the unreacted aluminum wastes, then adding another $100 \mathrm{~mL}$ of solution, but in a non-alcoholic medium, and also waiting for the reaction to stop. Both the process yields and the total yield are related to the hydrogen that could be obtained by stoichiometry with $100 \%$ pure aluminum. As proved, the purity of the aluminum and its shape is fundamental for a properly functioning system.

Table 8. Hydrogen flow rate generated for $100 \mathrm{~mL}$ of $7.5 \mathrm{M} \mathrm{NaOH}$ solution in an alcoholic medium. Hydrogen flow is generated at the end of the process or reaction in an alcoholic medium, isopropyl alcohol. Total flow rate by adding 7.5 M NaOH solution in a non-alcoholic medium. Yields of the alcoholic process and total non-alcoholic yield related to stoichiometric yield with $100 \%$ pure aluminum.

\begin{tabular}{cccccc}
\hline Aluminum Type & $\begin{array}{c}\text { Hydrogen 100 mL Solution } \\
\text { (L) }\end{array}$ & $\begin{array}{c}\text { Hydrogen End-of-Process } \\
\text { (L) }\end{array}$ & $\begin{array}{c}\text { Hydrogen Total } \\
\text { (L) }\end{array}$ & $\begin{array}{c}\eta_{\text {process }} \\
\text { (\%) }\end{array}$ & $\begin{array}{c}\eta_{\text {total }} \\
\text { (\%) }\end{array}$ \\
\hline Pure aluminum A4 & 30.5 & 38.9 & 38.9 & 99.7 & 99.7 \\
\hline $\begin{array}{c}\text { Automotive } \\
\text { aluminum A2 }\end{array}$ & 21.8 & 32.2 & 34.6 & 82.6 & 88.7 \\
\hline $\begin{array}{c}\text { Aeronautical } \\
\text { aluminum A3 }\end{array}$ & 20.8 & 29.9 & 33.3 & 76.7 & 85.4 \\
\hline
\end{tabular}

\subsection{Purity of Hydrogen}

The purity of the hydrogen obtained was analyzed, just in case the aluminum wastes contained any volatile or reactive elements that could generate some undesirable gas. No $\mathrm{CO}, \mathrm{C}_{1}-\mathrm{C}_{6}$ hydrocarbons, or $\mathrm{C}_{1}-\mathrm{C}_{3}$ oxygenate compounds were detected in the gas micro chromatograph. No alkali was detected by $\mathrm{pH}$ analysis. Hydrogen purity was greater than $98 \%$ in all cases, with impurities in the air $(<0.06 \%)$, alcohol $(<0.007 \%)$, and water $(>1.28 \%)$. This was due to the lack of tightness of the system connections since it is made of glass, 
which allows the air to pass through the circuit, and the use of a water filter that generates more moisture than the dryer can absorb. The alcohol obtained after condensation and filtration, for hydrogen flow rates lower than $3 \mathrm{~L} / \mathrm{min}$, was negligible $(<0.007 \%)$, but a perfect design of the condenser as a function of the flow rate is extremely important.

\subsection{Purity of Aluminum Hydroxide}

The purity of the aluminum hydroxide obtained from the sodium tetrahydroxyaluminate resulting from the reaction after filtration was finally analyzed. First, it is easy to isolate the alcohol from the aluminate solution. It can be carried out by decantation due to the lower density of the alcohol, or by its extinction in the oven due to evaporation. Concerning the aluminate solution, it is always together with unreacted solid aluminum particles or their alloying elements, which must be separated by porous filters. Then it is necessary to reduce its $\mathrm{pH}$ and start crystalizing the aluminum hydroxide. After the crystallization, washing is carried out [26], finally being introduced into an oven at $1000{ }^{\circ} \mathrm{C}$ to get the aluminum oxide.

From the results obtained (Table 9), it was seen that the content of aluminum in aluminum oxide was higher in aluminum waste from the automotive industry than in those from the aeronautical industry. The content of zinc in the alloy damages its purity due to the appearance of zinc oxides [27]. Silicon also brings impurities to the hydroxide, but far less than the previous ones. It would be necessary to generate hydrogen from low-zinc aluminum products or eliminate such impurities in the aluminum in the final product.

Table 9. Analysis of the purity of aluminum oxide obtained.

\begin{tabular}{cccc}
\hline Aluminum Type & $\begin{array}{c}\text { Initial Impurities (\%) } \\
\text { Cu-Zn-Fe-Si }\end{array}$ & $\begin{array}{c}\text { Final Impurities (\%) } \\
\text { Cu-Zn-Fe-Si }\end{array}$ & Content Al (\%) \\
\hline A4 (pure) & $<0.05$ & $<0,01$ & 24.4 \\
\hline A2 (automotive) & $1.5-0.7-0.5-5$ & $<0.01-0.11-0.02-0.19$ & 24.3 \\
\hline A3 (aeronautical) & $1-5-0.2-0.5$ & $<0.01-0.75-0-0.04$ & 23.2 \\
\hline
\end{tabular}

\subsection{Economic Study}

When studying whether this system is profitable, it is usually done from an energy point of view, assuming that aluminum is manufactured only to generate hydrogen and not as waste, so it is not viable [28], in this section, it is studied from an economic point of view.

The price of the aluminum machining chips ( USD 0.6/ $\mathrm{kg}$ (LME, London Metal Exchange 2020)) is low, and it could be used for green hydrogen production [29]. As can be seen in Table $10.9 \mathrm{~kg}$ of aluminum is needed to obtain $1 \mathrm{~kg}$ of hydrogen, so the cost would be USD $5.4 / \mathrm{kg} \mathrm{H}_{2}$. However, the residue obtained is $3.7 \mathrm{~kg} \mathrm{Al}_{2} \mathrm{O}_{3}$ whose cost is $\sim \mathrm{USD} 0.3 / \mathrm{kg} \mathrm{Al}_{2} \mathrm{O}_{3}$ (LME 2020) so the final cost, without considering the operating costs of $10 \%$, would be USD $4.3 / \mathrm{kg} \mathrm{H}_{2}$.

Table 10. Cost of aluminum green hydrogen.

\begin{tabular}{|c|c|c|c|c|}
\hline $\begin{array}{c}\text { Price Aluminum } \\
\text { Breakage Scrap }\end{array}$ & Price $\mathrm{Al}_{2} \mathrm{O}_{3}$ & $\begin{array}{c}\text { Cost } / \mathrm{kg} \text { Hydrogen } \\
(9 \mathrm{~kg} \mathrm{Al})\end{array}$ & $\begin{array}{c}\text { Sale } \mathrm{Al}_{2} \mathrm{O}_{3} \\
\left(3.7 \mathrm{kgAl}_{2} \mathrm{O}_{3} / \mathrm{kg} \mathrm{Al}\right)\end{array}$ & $\begin{array}{c}\text { Cost/kg Hydrogen } \\
\text { Total }\end{array}$ \\
\hline USD 0.6/kg Al & $0.3 \$ / \mathrm{kg} \mathrm{Al}{ }_{2} \mathrm{O}_{3}$ & $5.4 \$ / \mathrm{kg} \mathrm{H}_{2}$ & $1.1 \$ / \mathrm{kg} \mathrm{H}_{2}$ & $4.3 \$ / \mathrm{kg} \mathrm{H} 2$ \\
\hline
\end{tabular}

\section{Conclusions}

The main conclusion drawn from this research is the possibility of obtaining highpurity green hydrogen from aluminum wastes in a controlled manner by dosing the $7.5 \mathrm{M} \mathrm{NaOH}$ solution in an alcoholic medium with isopropyl alcohol, and the fact that this system is economically profitable. 
The active aluminum surface is enough to work as a function of the water flow (contained in the $\mathrm{NaOH}$ solution) only, to obtain the desired hydrogen flow rate continuously. The theoretically required surface to ensure an average hydrogen flow rate of $1 \mathrm{~L} / \mathrm{min}$ was estimated at $220 \mathrm{~mm}^{2}$ approximately. The theoretical formulas for calculating the active surface and the hydrogen flow rate to be obtained, have been studied, knowing that the addition of alcohol will decrease the yield, which has not been analyzed in this article. If the aluminum is recycled, it would be convenient to grind it to granular form and evaluate its impurities. Different aluminum wastes from industry after a machining process were tested. Those used in workshops and the automotive industry performed better than those used in the aeronautical industry, although in both cases the hydrogen obtained was more than $80 \%$ of the theoretically expected hydrogen. The purity of the hydrogen obtained was high. Its main impurity was moisture, and no element could affect the durability of the fuel cell, but in any case, a filter should be placed to eliminate escaping alcohol vapors from the condenser, and an excellent purging and connection should be done to prevent the entrance of air from the outside.

It has also been concluded that an almost constant hydrogen flow rate can be achieved by this method, regardless of the amount of aluminum in the reactor, by controlled dosing of $\mathrm{NaOH}$ solution in an alcoholic medium, also controlling the refrigeration and filtration of the sodium hydroxide particles. Finally, the derived sodium hydroxide obtained has zinc and some silicon impurities, so aluminum wastes from the automotive industry are preferred to those from the aeronautical industry. In any case, such impurities should be eliminated in the treatment of the final derived products to be able to commercialize them. With this analysis, an important contribution to the metal aluminum waste valorization has been performed and developed, giving a second life to this type of waste. This process could be used for metal industries that produce, yearly, tones of metal aluminum wastes, for instance, the automotive and aerospace industries. Other industries such as metal recovery plants or industries, which work with aluminum, could also be interested in the described study-analysis.

So, finally, summarizing, it was determined that it is possible to obtain green hydrogen from aluminum at a lower price than other methods by choosing the appropriate machining waste and evaluating sectors like automotive or aerospace, where it is possible to obtain better performance. Likewise, a model was developed to determine the amount of hydrogen obtained as a function of the chip geometry and the dissolution temperature.

Author Contributions: X.S.B.: conceptualization, methodology, formal analysis, supervision, project administration, funding acquisition. M.M.-G.: software, validation, visualization, writing-review \& editing; J.M.D.-M.: investigation, resources, data curation, writing-original draft preparation. All authors have read and agreed to the published version of the manuscript.

Funding: This research received no external funding.

Data Availability Statement: Not applicable.

Conflicts of Interest: The authors declare no conflict of interest.

\section{References}

1. Abánades, A. The challenge of Hydrogen production for the transition to a $\mathrm{CO}_{2}$-free economy. Agron. Res. Biosyst. Eng. Spec. 2012, 1, 11-16.

2. Widera, B. Renewable Hydrogen implementations for combined energy storage, transportation, and stationary application. Therm. Sci. Eng. Prog. 2020, 16, 100460. [CrossRef]

3. Ball, M.; Weeda, M. The hydrogen economy, vision or reality? Compend. Hydrogen Energy 2016, 40, $237-266$.

4. Wang, H.Z.; Leung, D.Y.C. A review on hydrogen production using aluminum and aluminum alloys. Renew. Sustain. Energy Rev. 2009, 13, 845-853. [CrossRef]

5. Woodall, J.M.; Ziebarth, J.T.; Allen, C.R.; Jeon, J.; Choi, G.; Kramer, R. Generating hydrogen on demand by splitting water with Al-rich alloys. Clean Technol. 2008, 5, 313-315.

6. Lin, Y.; Genzer, J.; Dickey, M.D. Attributes, Fabrication and Applications of Gallium-Based Liquid Metal Particles. Adv. Sci. 2020, 7, 2000192. [CrossRef] 
7. Pyun, S.I.; Moon, S. Corrosion mechanism of pure aluminum in aqueous alkaline solution. J. Solid State Electrochem. 2000, 4, 267-272. [CrossRef]

8. Huang, X.N.; Liu, S.; Wang, C.; Chen, D.; Huang, Y.X. On-Demand Hydrogen Generator Based on the Reaction between Aluminum Slurry and Alkaline Solution. Adv. Mater. Res. 2012, 347-353, 3242-3245. [CrossRef]

9. Rami, A.; Lasia, A. Kinetics of hydrogen evolution on Ni-Al alloy electrodes. J. Appl. Electrochem. 1992, 22, 376-382. [CrossRef]

10. Razavi-Tousi, S.S.; Szpunar, J.A. Effect of structural evolution of aluminum powder during ball milling on hydrogen generation in aluminum water reaction. Int. J. Hydrogen Energy 2012, 38, 795-806. [CrossRef]

11. Hakenjos, A.; Muenter, H.; Wittstadt, U.; Hebling, C. A PEM fuel cell for the combined measurement of current and temperature distribution, and flow field flooding. J. Power Sources 2004, 131, 213-216. [CrossRef]

12. Petrovic, J.; Thomas, G. Reaction of Aluminum with Water to Produce Hydrogen. A Study of Issues Related to the Use of Aluminum for On-Board Vehicular Hydrogen Storage; U.S. Department of Energy: Washington, DC, USA, 2008.

13. Parmuzina, A.V.; Kravchenko, O.V.; Bulychev, B.M.; Shkolnikov, E.I.; Burlakova, A.G. Oxidation of activated aluminum with water as a method for hydrogen generation. Russ. Chem. Bull. 2009, 58, 493-498. [CrossRef]

14. Eom, K.S.; Cho, E.A.; Kwon, H.S. Feasibility of on-board hydrogen production from hydrolysis of AleFe alloy for PEMFCs. Int. J. Hydrogen Energy 2011, 36, 12338-12342. [CrossRef]

15. Wang, E.D.; Shi, P.F.; Du, C.Y.; Wang, X.R. A mini-type hydrogen generator from aluminum for proton exchange membrane fuel cells. J. Power Sources 2008, 181, 144-148. [CrossRef]

16. Akansu, S.O.; Dulger, Z.; Kahraman, N.; Veziroğlu, T.N. Internal combustion engines fueled by natural gas-Hydrogen mixtures. Int. J. Hydrogen Energy 2004, 29, 1527-1539. [CrossRef]

17. Teng, H.T.; Lee, T.Y.; Chen, Y.K.; Wang, H.W.; Cao, G. Effect of $\mathrm{Al}(\mathrm{OH}) 3$ on the hydrogen generation of aluminum-water system. J. Power Sources 2012, 219, 16-21. [CrossRef]

18. Schlapbach, L.; Züttel, A. Hydrogen-storage materials for mobile applications. Nature 2001, 414, 353-357. [CrossRef]

19. Salueña-Berna, X.; Mujal-Rosas, R.; Dagà-Monmany, J.M.; Colom, X. Método para generar hidrógeno a partir de residuos de aluminio, para alimentar la pila de combustible de un coche de radio control. DYNA 2019, 94, 12-15. [CrossRef]

20. Razavi-Tousi, S.S.; Szpunar, J.A. Mechanism of corrosion of activated aluminum particles by hot water. Electrochim. Acta 2014 127, 95-105. [CrossRef]

21. Shaytura, N.S.; Laritchev, M.N.; Laritcheva, O.O.; Shkolnikov, E.I. Study of texture of hydroxides formed by aluminum oxidation with liquid water at various activation techniques. Curr. Appl. Phys. J. 2010, 10, 1567-1739. [CrossRef]

22. Hu, H.; Qiao, M.; Pei, Y.; Fan, K.; Li, H.; Zong, B.; Zhang, X. Kinetics of hydrogen evolution in alkali leaching of rapidly quenched Ni-Al alloy. Appl. Catal. A. Gen. 2003, 252, 173-183. [CrossRef]

23. Mahmoodi, K.; Alineiad, B. Enhancement of hydrogen generation rate in reaction of aluminum with water. Int. J. Hydrogen Energy 2010, 35, 5227-5232. [CrossRef]

24. Park, Y.K.; Tadd, E.H.; Zubris, M.; Tannenbaum, R. Size-controlled synthesis of alumina nanoparticles from aluminum alkoxides. Mater. Res. Bull. 2005, 40, 1506-1512. [CrossRef]

25. Macanás, J.; Soler, L.; Candela, A.M.; Muñoz, M.; Casado, J. Hydrogen generation by aluminum corrosion in aqueous alkaline solutions of inorganic promoters. The Alhydrox process. Energy 2011, 36, 2493-2501. [CrossRef]

26. Huang, S.-Y.; Wang, C.-C.; Lin, C.-L.; Tsai, Y.-L.; Chao, C.-G.; Liu, T.-F. Mechanism of aluminum-induced lateral crystallization of amorphous silicon. Jpn. J. Appl. Phys. 2010, 49, 2493-2501. [CrossRef]

27. Khodadad, E.; Lei, M.K. Mathematical modeling for hard trivalent chromium coatings thickness with thin zincates interlayer on pure aluminum. Int. J. Electrochem. Sci. 2014, 9, 1250-1263.

28. Keane, E.; Browne, D.J.; Carr, A.J. Experimental and economic study of aluminium-gallium alloys as a fuel/catalyst for hydrogen propulsion. In Proceedings of the SEEP 2009: International Conference on Sustainable Energy \& Environmental Protection, Dublin, Ireland, 12-15 August 2009; pp. 12-15.

29. Takehito, H.; Takeuchi, M.; Hisa, M.; Akiyama, T. Hydrogen Production from Waste Aluminum at Different Temperatures, with LCA. Mater. Trans. 2005, 46, 1052-1057. 